\title{
Discovering the Environment
}

\author{
by \\ Albert Bergesen \\ Department of Sociology \\ University of Arizona \\ Tucson, Arizona 85721 \\ albert@u.arizona.edu \\ and \\ Laura Parisi \\ Department of Political Science \\ Virginia Polytechnic Institute and State University \\ Blacksburg, VA 24061 \\ Iparisi@vt.edu
}

Cite: Bergesen, Albert and Laura Parisi. (1997). "Discovering the Environment." Journal of World-Systems Research (http://jwsr.ucr.edu/) 3: 364 - 368.

C 1997 Albert Bergesen and Laura Parisi.

[Page 364]

Journal of World-Systems Research

This special issue of JWSR presents new research on the environment from a distinctly world-system perspective. World-system studies have recently discovered the environment. The turn toward the environment in any number of disciplines has resulted in the greening of this and that area of study. Now it is world-system studies turn. It is a little late; but better late than never. Actually, environmental and world-system studies have a great deal to offer each other. For environmental studies the focus upon the world economy as a whole makes a great deal of sense. Industrial plants in one country, or one region of the world may generate acid rain, but it can fall on other countries. The environment knows no political borders, hence a focus upon the world economy rather than the French, American or Brazilian economy, makes more sense. It is also the case that looking for systemic effects of different types of economies and political systems on the environment should follow the general direction of political/economic theory, which has been ratcheting its level of analysis ever upward to include more and more parts of the world as components of a singular world system. In effect, if we now believe that the most primal locus of economic and political process resides at the level of global interactions then to study the effects of political/economic processes upon the environment means studying the dynamics of the world-system. It is somewhat inevitable. 
Having said this, it is also clear that there is not an obvious link between the operational logic of the world system and subsequent environmental degradation. This is probably a corollary to the fact that core countries have a disproportionate amount of the world's surplus, in that they disproportionately use more resources, pollute and emit more toxins, etc. However, that hypothesis could be offered by traditional societal level analysis: bigger, richer countries use and abuse more of the environment. The core-periphery aspect of world system theory might suggest that dependent development also creates more environmental degradation--large core based multinationals to extracting resources and destroying the environment. The validity of that proposition awaits evaluation by systematic data.

World-system implications for environmentalism, then, can potentially take a number of forms. One is to repeat arguments linking forms of economic organization (capitalism degrades the environment, to take one) that have been argued to produce environmental degradation and ratchet those up to the global, or world systemic level of analysis. It is the operational logic of the world economy, or the capitalist world economy, that devours resources and degrades planet Earth. Second, the core-periphery model may have implications for the differential environmental effects, although the logic here may go in the opposite direction, as highly industrialized core states appear to emit the most toxic materials and proportionally consume most of the most natural resources. Ironically, then, dependent development, to the extent that it means less industrial development and specializing in raw material production, may also mean less damage to nature (though obviously mineral extraction or the destruction of forests have negative effects). Extreme economic backwardness may mean less environmental degradation, and lower standards of living may also mean less raw material consumption. Here the core-periphery model would seem to have differential effects upon humans versus the environment. Being in the core is good for humans--high income, high consumption, high standards of living-but bad for nature, which pays the price for these human advantages. Being in the periphery is bad for humans: low standards of living, low levels of consumption--but this is good for the environment, as less is extracted and used.

[Page 365]

Journal of World-Systems Research

What this suggests is a potential opposition in terms of human vs. nature's betterment. Bettering the human condition, in traditional terms means raising the standards of living, but that comes at the expense of nature. Bettering the condition of nature means leaving it alone, acknowledging its right to live as wilderness untouched by human development. Now this may be a false opposition, and theorists of "sustainable development" would suggest we can have our development/environmental pie and eat it too. Maybe. But the opposition of humans wanting more and nature wanting to be left alone may be a conflictual situation that cannot be massaged with ideas like sustainable development or the ideology that less is more. Maybe that's true. Who knows? But it would seem a difficult sell to the developing world, which has yet to have had more and must now 
consider having less. People already at the poverty, if not starvation level, are hard to recruit to the campaign of having even less. This position may remain popular only in the developed world. If the human and nature projects are in opposition reconciling them may be the biggest task facing both environmental and world-system theory. Less is more and sustainable development are two solutions on the table. Whether they will turn out to be sustainable answers remains to be seen.

This special issue of the Journal of World-Systems Research contains a variety of papers that deal with the interface of environmental and world-system studies. Some were presented at a recent PEWS session at the American Sociological Association's annual meetings and others were submitted to this special issue. The articles in this special issue share a common main point: thinking and theorizing about environmental or ecological issues is vital to our understanding of global change. The authors make this point through a variety of approaches, each of which is briefly discussed below.

Bartley and Bergesen provide a review of the small but growing literature surrounding the environment and world-systems analysis. They analyze the literature in four topic areas: environmental degradation, natural resources and development, environmental constraints and social change, and regimes, movements, and world polit ics. The authors find that there are some general conclusions one can draw from reviewing the literature on world-systems and the environment. For example, several studies indicate that core countries experience less deforestation than semiperipheral countries. There is also evidence that there may be an "environmental Kuznets curve" in regards to greenhouse gas emissions and toxic emissions. The review of the literature suggests that natural resource strategies are an important component of the rise of peripheral countries to semiperipheral status as well as achieving hegemonic status in the world system. Indeed, several studies also indicate the importance of ecological degradation in altering social structures in the world-system and the world-system itself. Finally, the literature points to a growing awareness among the global community that global cooperation is vital to solving environmental problems. There has been an increase in environmental treaties as well as environmental social movements. Interestingly enough however, participation in treaties and the location of these burgeoning social movements is affected by worldsystem position. Core countries tend to participate in environmental treaties more frequently than non-core countries whereas semiperipheral and peripheral countries are increasingly the sites for new environmental social movements.

[Page 366]

Journal of World-Systems Research

Chew provides a more theoretical overview and analysis of the relationship between the world system and the environment. He argues that world-system analysis would be more accurate if ecological considerations are included in theorizing because contemporary world-systems theory is too focused on the social or anthropocentric dimensions of global processes. In order to understand global change, we must introduce and incorporate a 
ecological dimension (our relations with Nature) to the analysis. The end result would be a shift from humancentric approaches to understanding global dynamics to what he calls an ecocentric one. This perspective entails understanding "the ecological relationships between human and other living beings and natural processes as a basic dimension defining the trends and dynamics of the world-system" (p. 384) rather than viewing environmental phenomena as an outcome of system dynamics. He applies the ecocentric paradigm to several system phenomena, such as accumulation processes and cycles, core periphery relations and hegemonic rivalry, and crises and world-views to reveal quite different explanations for global processes. For example, in his application of the ecocentric paradigm to core-periphery relations, Chew concludes that continuous environmental degradation caused by core-sponsored development in the periphery has a long-term effect on the future relocation of production. The application of an ecocentric world-system theory can help us pursue ecological integrity and justice that a humancentric one cannot.

Chase-Dunn and Hall also argue that examining ecological processes is necessary to our understanding of world-system change/evolution. Focusing on factors such as population pressure and ecological depletion, the au thors develop a conceptual model for comparing world-systems. They find that different types of world-systems (e.g. simple to complex) face the same environmental concerns and challenges and that ecological concerns are a major impetus behind the development of social structures. However, the consequences of environmental degradation vary over time and space. For example, the authors contend that since the modern world system is global, the "possibilities of escape from ecological ruin are greatly reduced" (p. 419). Earlier system configurations were more able to deal with environmental degradation and population pressure because they "could expand spatially in order to resolve internal contradictions" (p. 419). Hence, the contemporary world system, despite technological advances, is less able to resolve problems of environmental degradation due to its sheer size, precluding any spatial expansion. Although the authors are pessimistic about the ability of capitalism and the modern world system to effectively solve the problems that ecological depletion produces, they offer some potential future scenarios that may help us achieve sustainable development.

[Page 367]

Journal of World-Systems Research

Some world-systems scholars approach environmental problem-solving through the use of quantitative studies. For instance, Burns, et al., argue that there is a lack of quantitative, cross-national research that examines the effects of social processes on environmental outcomes. Their study on the social antecedents of greenhouse gas emissions ( $\mathrm{CO}_{2}$ and $\left.\mathrm{CH} 4\right)$ attempts to fill this void. Furthermore the study is grounded in a world-systems perspective as they theorize that the "social dynamics of leading to $\mathrm{CO} 2$, $\mathrm{CH} 4$ and to environmental degradation generally, may operate quite differently across structural positions in the world system" (p. 435). In order to test this theory, they test the effects of social dynamics, operationalized as level of economic developme nt (GNP), 
energy consumption, agricultural activity (total cattle population), and the amount of forested area in 1991, relative to 1960, of the core, semi-core, semiperiphery, and periphery on two dependent variables: $\mathrm{CO} 2$ emissions from industrial sources and $\mathrm{CH} 4$, or methane, emissions, since both types of emissions contribute to the greenhouse effect. Their main findings are that $\mathrm{CO} 2$ emissions are most closely related to the core position in the world-system whereas $\mathrm{CH} 4$ emissions are most closely related with the semi-core position. However, the social dynamics that are associated with the type and amount of emissions are quite different in the core and semi-core. In the core, $\mathrm{CO} 2$ emissions are mediated by energy consumption, while in the semi-core, $\mathrm{CH} 4$ emissions are mediated by agricultural activity and shifting patterns of industrialization.

All of the articles in this special issue of Joumal of World-Systems Research argue that the time for world-systems research to "discover" the environment is here and indeed imperative if we are to understand, and possibly influence, global change. We hope that these articles will help provide a theoretical and empirical blueprint for more "green" world-systems analyses.

[Page 368]

Journal of World-Systems Research 